\title{
Effect of blend ratio on aging, oil and ozone resistance of silica-filled chloroprene rubber/natural rubber (CR/NR) blends
}

\author{
P. Sae-oui ${ }^{1,2^{*}}$, C. Sirisinha ${ }^{2,3}$, K. Hatthapanit ${ }^{1}$ \\ ${ }^{1}$ National Metal and Materials Technology Center, 114 Thailand Science Park, Paholyothin Rd., Klong 1, Klong-Luang, \\ Pathumthani 12120, Thailand \\ ${ }^{2}$ Rubber Research Unit, Faculty of Science, Mahidol University, Salaya Campus, Phutthamonthon 4 Rd., Salaya, \\ Nakornprathom 73170, Thailand \\ ${ }^{3}$ Department of Chemistry, Faculty of Science, Mahidol University, Rama 6 Rd., Rajdhevee, Bangkok, 10400, Thailand
}

Received 18 October 2006; accepted in revised form 2 December 2006

\begin{abstract}
The effect of blend ratio on properties of chloroprene rubber/natural rubber (CR/NR) blends was investigated. In addition to the mechanical properties, attention was also given to the resistance to thermal aging, oil and ozone of the blends. Silica was selected as a reinforcing filler in this study due to its unique characteristic to interact with CR. The results reveal that, due to the better filler dispersion and the greater crosslink density, the silica-filled CR possesses lower compound viscosity and better mechanical properties, compared to the silica-filled NR. The aging properties, oil and ozone resistance of the silica-filled CR are also significantly better than those of the silica-filled NR. The mechanical properties and the resistance to degradation of the silica-filled CR/NR blends are mainly governed by the blend morphology. It is found that good mechanical properties in association with adequately high resistance to degradation from thermal aging and oil are obtained when CR remains the matrix in the blends. Even though the ozone cracks are found in all blends, a thorough look at the results reveals that considerable improvement in ozone resistance is achieved with increasing CR content.
\end{abstract}

Keywords: rubber, blend, oil resistance, aging resistance, mechanical properties

\section{Introduction}

Rubber blends have gained much attention in the rubber industry because, when properly formulated, the blend could combine the best features of the individual blend partner. Desirable outcome is therefore easily obtained. Natural rubber (NR) is widely known to possess good mechanical properties such as high tensile and tear strengths due to its ability to crystallize upon stretching. The elasticity and dynamic properties of NR are also excellent. However, due to the existence of numerous reactive double bonds on the molecular backbone, NR is highly susceptible to degradation by thermal aging and ozone attack. In addition, oil resistance of NR is relatively poor, compared to some polar synthetic rubbers such as chloroprene rubber (CR) or acrylonitrile butadiene rubber (NBR). To overcome such shortcomings, NR is frequently blended with synthetic rubbers such as NBR or CR. Recently, blends of NR/CR have been extensively studied [1-4]. The incorporation of CR into NR helps to improve oil and thermal resistance of NR. As CR and NR are cured in different manners, careful adjustment of the cure system must be taken into account to avoid maldistribution of crosslinks within the two phases. Cure system of NR/CR blend therefore generally includes sulfur, thiourea derivatives with the addition of other conventional

"Corresponding author, e-mail: pongdhor@mtec.or.th

(c) BME-PT and GTE 
accelerators [5]. Apart from the curing system, the difference in polarity of the blend partners could also bring about high interfacial tension which is detrimental to the mechanical properties of the blend [6]. The addition of suitable compatibilizer is therefore recommended.

It has currently been reported that precipitated silica, widely used as reinforcing filler for most rubbers, could form strong interaction with $\mathrm{CR}$ through hydrogen bonds [7-8]. The presence of silica in $\mathrm{CR}$ could also give rise to additional crosslinks due to the chemical reaction between the silanol groups on silica surface and the allylic chlorine atoms in CR [9-10]. These reports confirm that silica interacts with $\mathrm{CR}$ in a special manner which is different from the most commonly used filler, carbon black. It is therefore interesting to use silica as a reinforcing filler for this CR/NR blend. In the present study, the effect of blend ratio on properties of silica-filled CR/NR blend was investigated. The mechanical properties as well as the resistance to aging, oil and ozone of the blends were focused.

\section{Experimental}

\subsection{Materials}

All mixing ingredients were used as received. Polychloroprene (CR, Neoprene W) with the Mooney viscosity of $44-\mathrm{ML} 1+4 @ 100^{\circ} \mathrm{C}$ was supplied by DuPont Dow Elastomers PTE Ltd. Natural rubber (NR, STR 5L) with the Mooney viscosity of 74-ML1+4@100 ${ }^{\circ} \mathrm{C}$ was manufactured in Thailand by Union Rubber Products Corp. Ltd. Silica (HiSil 255s with specific surface area of $175 \mathrm{~m}^{2} / \mathrm{g}$ ) was supplied by Tokuyama Siam Silica Co., Ltd. N-tert-butyl-2-benzothiazole sulfenamide (Santocure-TBBS) was obtained from Reliance Technochem (Flexsys) Co., Ltd. Stearic acid, zinc oxide $\left(\mathrm{ZnO}\right.$, white seal) and sulfur $\left(\mathrm{S}_{8}\right)$ were obtained from Kij Paiboon Chemical Ltd. (Thailand). Ethylene thiourea (ETU 22S) and magnesium oxide $(\mathrm{MgO})$ were manufactured in Japan by Kawakushi Co., Ltd. and Konoshima Chemical Co., Ltd., respectively.

\subsection{Preparation and testing of rubber compounds}

The compound formulation used in the present study is given in Table 1 . The mixing process was
Table 1. The compound formulation

\begin{tabular}{|l|c|c|c|c|c|}
\hline \multicolumn{1}{|c|}{ Ingredient } & \multicolumn{5}{c|}{$\begin{array}{c}\text { Loading } \\
\text { (parts per hundred of rubber, phr) }\end{array}$} \\
\hline Polychloroprene (CR) & 100 & 75 & 50 & 25 & 0 \\
\hline Natural rubber (NR) & 0 & 25 & 50 & 75 & 100 \\
\hline Zinc Oxide & 5 & 5 & 5 & 5 & 5 \\
\hline Stearic acid & 1 & 1 & 1 & 1 & 1 \\
\hline Magnesium Oxide & 4 & 4 & 4 & 4 & 4 \\
\hline Silica & 30 & 30 & 30 & 30 & 30 \\
\hline TBBS* & 1 & 1 & 1 & 1 & 1 \\
\hline Ethylene thiourea & 0.3 & 0.3 & 0.3 & 0.3 & 0.3 \\
\hline Sulfur & 2 & 2 & 2 & 2 & 2 \\
\hline
\end{tabular}

*N-tert-butyl-2-benzothiazole sulfenamide

carried out using a laboratory-sized internal mixer (Haake Rheomix 3000p). The mixing conditions were set as follows; fill factor $=0.7$, initial chamber temperature $=60^{\circ} \mathrm{C}$, rotor speed $=40 \mathrm{rpm}$ and mixing time $=12$ minutes. After mixing, the compounds were sheeted out on a two-roll mill (Collin W100T). Measurement of Mooney viscosity (MS1+4@100 ${ }^{\circ} \mathrm{C}$ ) was carried out using the Mooney viscometer (TechPro viscTECH+). The cure characteristics, e.g., scorch time $\left(t_{s} 2\right)$ and optimum cure time $\left(t_{c} 90\right)$ including minimum torque (ML) and maximum torque (MH) were determined using a moving die rheometer (MDR, TechPro $\mathrm{MD}+)$ at $155^{\circ} \mathrm{C}$. As it is reported earlier that the torque difference (MH-ML) is directly proportional to the degree of crosslinking, it is therefore employed to indirectly represent the crosslink density of the blend vulcanizates herein [11].

\subsection{Testing of rubber vulcanizates}

Vulcanization of the compounds was carried out using compression molding technique at $155^{\circ} \mathrm{C}$ based on the optimum cure time obtained from MDR. The tensile properties were determined using a universal testing machine (Instron 4301 series) following ISO 37 . The hardness was measured using a Wallace Shore A durometer according to ISO 868. Ozone resistance test was carried out according to ISO 1431/1. The rectangular specimens were stretched to $20 \%$ strain and conditioned at $40^{\circ} \mathrm{C}$ for 48 hours prior to testing. The conditioned specimens were then put into an ozone QUV resistance tester (Toyoseiki) at $40^{\circ} \mathrm{C}$ and 50 parts per hundred million (pphm) ozone concentration for 70 hours. The ozone cracks were thereafter determined. The thermal aging properties of the rubber vulcanizates were studied by placing the 
specimens in an aging oven at $100^{\circ} \mathrm{C}$ for 72 hours prior to the determination of tensile properties. Oil resistance was measured, according to ISO 1817 , by immersing the specimens in non-polar hydraulic oil (Shell-Tellus 100) for 7 days at room temperature $\left(23^{\circ} \mathrm{C}\right)$. After the immersion, the specimens were blotted off with filtered paper and rinsed with acetone prior to the determinations of mass change and tensile properties. In this study, the degree of filler dispersion and blend morphology were examined using a scanning electron microscope (SEM, JEOL JSM-5410) and an atomic force microscope (AFM, Multimode Nanoscope IIIA ), respectively. The SEM micrographs were taken on the newly exposed surface of the rubber specimens fractured immediately after embrittling in liquid nitrogen. The specimens were then sputtered with gold to prevent charging on the surface. The AFM micrographs were taken on the newly exposed surface cut from the microtome under sub-ambient condition.

\section{Result and discussion}

The dependence of Mooney viscosity on blend ratio is illustrated in Figure 1. As can be seen, the viscosity of the $\mathrm{CR} / \mathrm{NR}$ blend increases continuously with increasing NR content in the blends. This is attributed to the dilution effect because the results reveal that neat $\mathrm{CR}$ possesses the lowest viscosity whereas neat NR possesses the highest viscosity, i.e., the low viscosity $\mathrm{CR}$ portion is substituted by the high viscosity NR portion. Apart from the higher molecular weight of NR, the poor filler dispersion also contributes to the high viscosity of silica-filled NR. As silica is a highly polar filler whereas NR is considered as a non-polar elastomer, the rubber-filler interaction is therefore relatively low. On the contrary, the hydroxyl or silanol groups on silica surface could form hydrogen

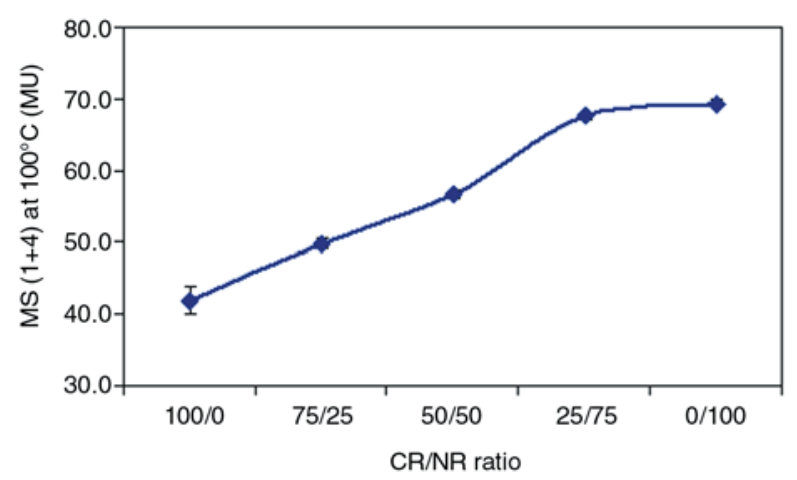

Figure 1. Effect of blend ratio on Mooney viscosity of the compounds bonds towards each other resulting in a strong filler-filler interaction. Disagglomeration of silica is therefore more difficult to take place leading to poor filler dispersion. However, in neat CR, the rubber-filler interaction is relatively high because $\mathrm{CR}$ contains chlorine atoms which could interact strongly with the silanol groups on silica surface. The degree of filler dispersion in neat CR is there-
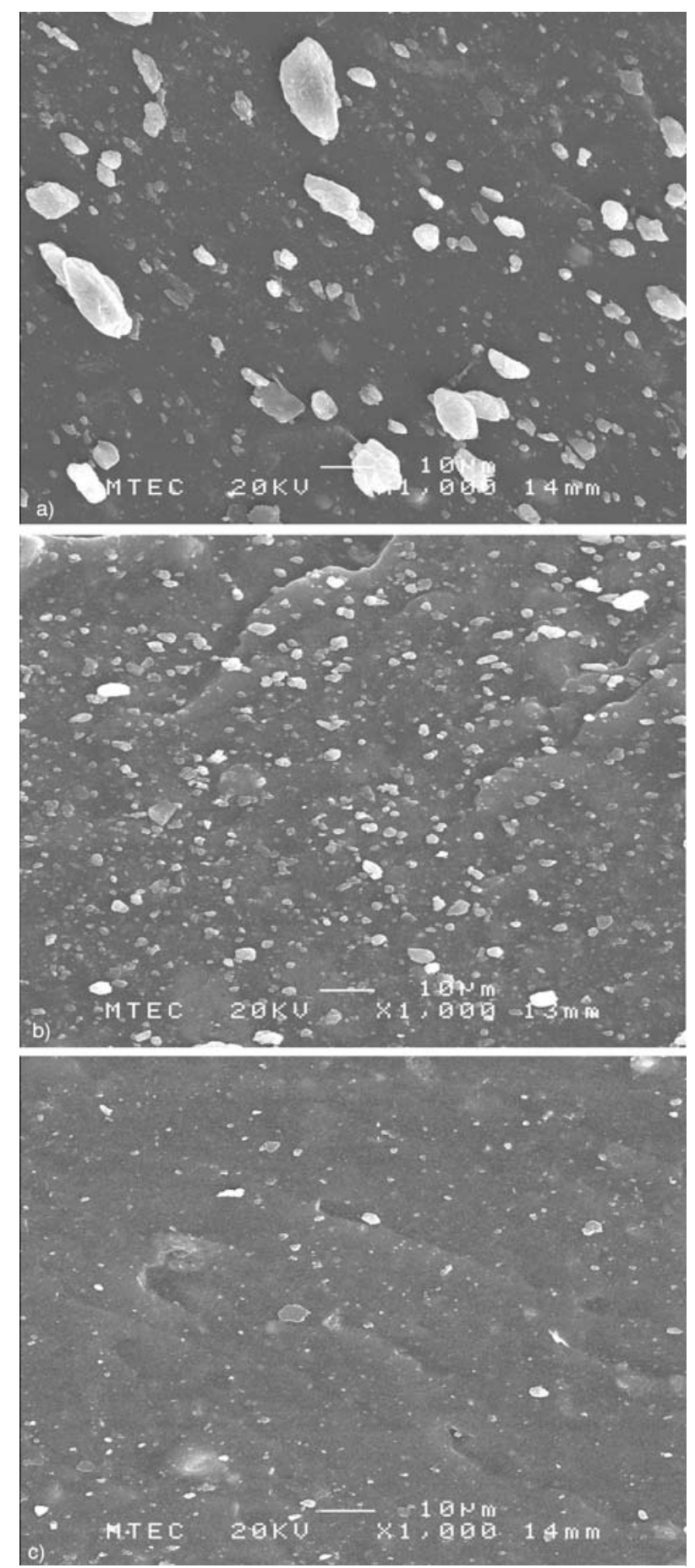

Figure 2. SEM micrographs of (a) silica-filled NR, (b) silica-filled 50/50 CR/NR blend and (c) silicafilled CR 


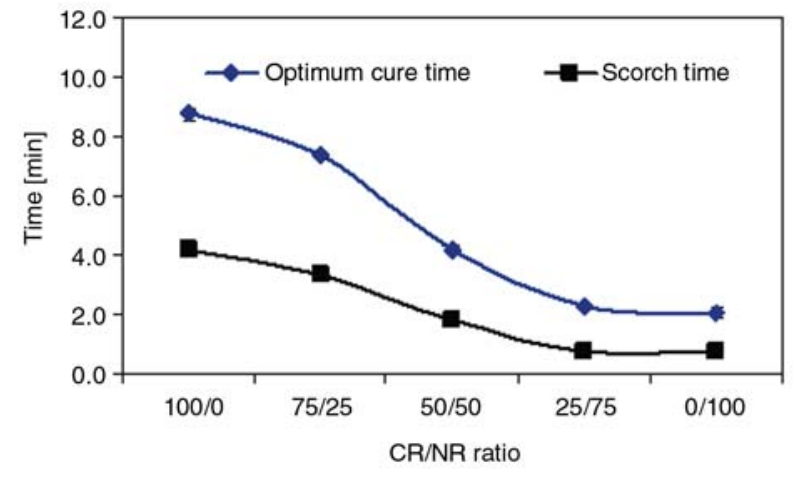

Figure 3. Effect of blend ratio on scorch time $\left(t_{s} 2\right)$ and optimum cure time $\left(t_{c} 90\right)$ of the compounds

fore higher than that in neat NR as shown in Figure 2.

Cure characteristics of the compounds were also investigated and the results are given in Figure 3. It is widely known that the double bonds in NR are more reactive to vulcanization reaction than those in $\mathrm{CR}$ and the non-rubber content in NR could also accelerate cure, neat NR therefore possesses significantly shorter scorch time and optimum cure time, compared to neat CR. Similar observation is also found in the work of Ismail, et al. [12] in which the longer Mooney scorch time of CR is explained by the curing nature of CR to prevent scorch [13]. Due to the dilution effect, both scorch time and optimum cure time are found to reduce consecutively with increasing NR content in the blend. Although cure rate is increased with increasing NR content, it is surprising that the state of cure or crosslink density, as measured from the torque difference ( $\mathrm{MH}-$ ML), follows the opposite trend, i.e., the crosslink density tends to reduce with increasing NR content in the blends as shown in Figure 4. The highest state of cure found in neat CR is thought to arise from the combination of crosslink obtained from conventional vulcanization and additional crosslink

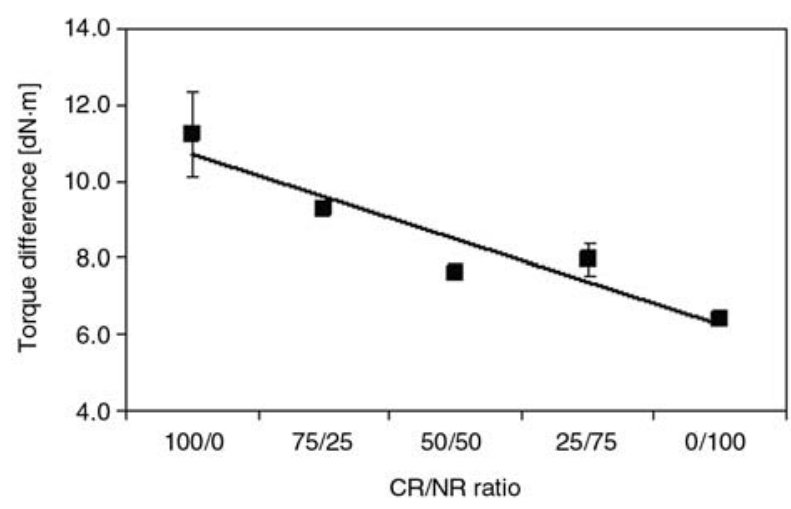

Figure 4. Dependence of torque difference on blend ratio from the chemical reaction between the silanol group on silica surface and the allylic chlorine atoms of CR [9]. On the other hand, the unexpectedly low state of cure found in neat NR is thought to take place from the retarding effect of silica. Due to the presence of sianol groups on silica surface, silica could adsorb zinc complex and amine accelerator giving rise to cure retardation and, thus, the reduction of crosslink density [14]. Again, due to the dilution effect, the state of cure of CR/NR blend is found to decrease with increasing NR content.

Table 2 represents the effect of blend ratio on tensile properties and hardness of the rubber vulcanizates. In this study, the tensile strength of neat NR is unexpectedly low because silica is added into the rubber without the addition of glycol, amine or silane coupling agent. The absence of such compound in neat NR leads to poor filler dispersion, poor rubber-filler interaction and low crosslink density. The tensile strength of neat NR is therefore relatively low, compared to neat CR. In addition, both $100 \%$ modulus and hardness of neat NR are lower than those of neat CR. Possible explanation is given to the lower state of cure of neat NR as mentioned earlier. As expected, these properties of the rubber blends tend to decrease with increasing NR content. This is attributed to the dilution effect. A thorough look at the tensile strength results also reveal that the reduction of tensile strength with increasing NR content does not follow the mixture rule, i.e., the tensile strength is reduced slightly with increasing NR content up to 50/50 CR/NR ratio. Further increase in NR content results in a sharp drop of tensile strength. The blend morphology could be used to explain the results. The AFM micrographs of the blends at various blend ratios are given in Figure 5. The results clearly reveal that, for both $75 / 25$ and $50 / 50 \mathrm{CR} / \mathrm{NR}$ blends, $\mathrm{CR}$ is the continuous phase (represented by the dark area) and NR is the dispersed phase (represented by the light area). Most properties of these blends there-

Table 2. Effect of blend ratio on tensile properties and hardness of the vulcanizates

\begin{tabular}{|c|c|c|c|}
\hline $\begin{array}{c}\text { CR/NR } \\
\text { Blend ratio }\end{array}$ & $\begin{array}{c}\text { Tensile } \\
\text { strength } \\
{[\mathbf{M P a}]}\end{array}$ & $\begin{array}{c}\mathbf{1 0 0 \%} \\
\text { Modulus } \\
{[\mathbf{M P a}]}\end{array}$ & $\begin{array}{c}\text { Hardness } \\
\text { [Shore A] }\end{array}$ \\
\hline $100 / 0$ & $25.8 \pm 0.5$ & $1.54 \pm 0.05$ & $59.9 \pm 0.4$ \\
\hline $75 / 25$ & $23.8 \pm 0.9$ & $1.35 \pm 0.03$ & $57.1 \pm 0.6$ \\
\hline $50 / 50$ & $24.0 \pm 1.0$ & $1.14 \pm 0.06$ & $53.2 \pm 0.4$ \\
\hline $25 / 75$ & $18.2 \pm 1.0$ & $1.07 \pm 0.04$ & $51.7 \pm 0.6$ \\
\hline $0 / 100$ & $12.4 \pm 1.1$ & $0.92 \pm 0.02$ & $50.3 \pm 1.2$ \\
\hline
\end{tabular}



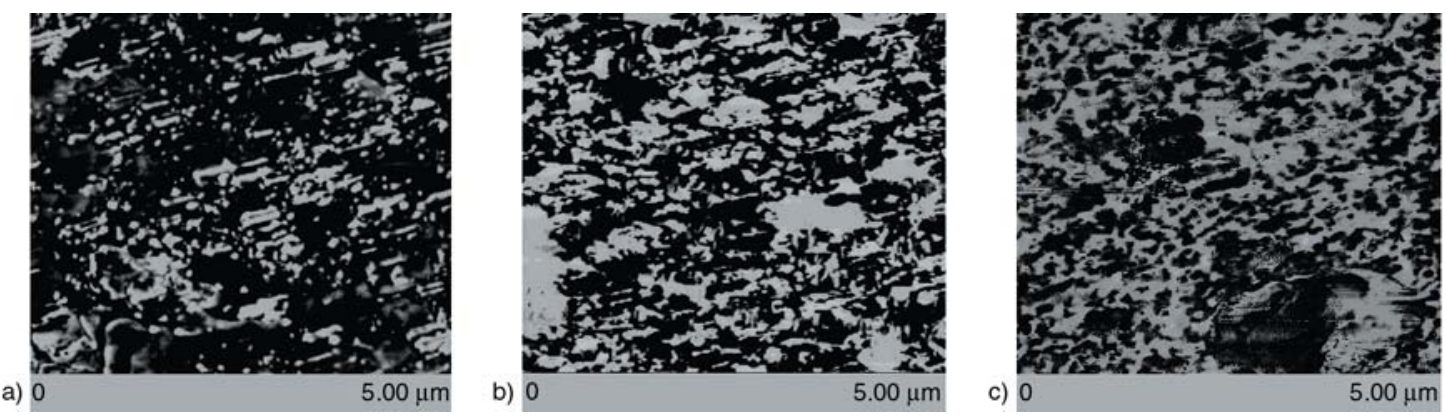

Figure 5. AFM micrographs of (a) 75/25 CR/NR blend, (b) 50/50 CR/NR blend and (c) 25/75 CR/NR blend

fore resemble those of neat CR. Similar observation has been previously reported for chlorinated polyethylene/natural rubber (CPE/NR) blend by Sirisinha, et al. [15] At 25/75 CR/NR ratio, phase inversion takes place and most properties of the blend are mainly controlled by the NR matrix. It could also be observed that both $100 \%$ modulus $\left(\mathrm{M}_{100}\right)$ and hardness are reduced with increasing NR content in the blends. This is understandable because silica accelerates and increases state of cure in CR whereas, for NR, it shows cure retarding effect resulting in the reduction of crosslink density and, thus, modulus and hardness. Increasing NR content in the blend therefore gives rise to a softer silica-filled vulcanizate.

The effect of blend ratio on aging resistance which is represented in terms of the relative value (the ratio of the properties after aging to those before aging) is illustrated in Figure 6. The results reveal that, regardless of blend ratio, aging at high temperature leads to the reduction of tensile strength (the relative tensile strength is less than 1). As the double bonds in CR are less reactive to thermal oxidative degradation, $\mathrm{CR}$ is more resistant to thermal aging than NR as can be seen from the higher relative tensile strength. Again, due to the dilution effect, the aging resistance of the blends is found to

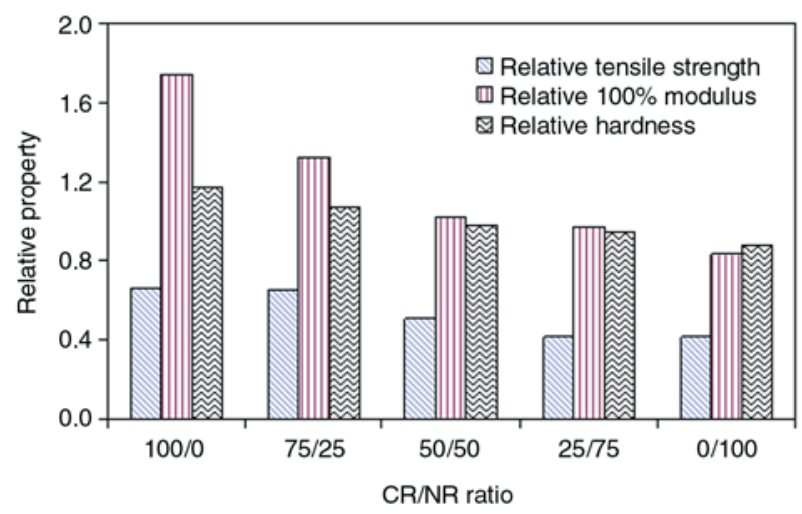

Figure 6. Effect of blend ratio on thermal aging resistance (represented in terms of the relative properties) reduce with increasing NR content. At 25/75 $\mathrm{CR} / \mathrm{NR}$ ratio where NR becomes the matrix, the aging resistance of the blend is similar to that of neat NR.

For the relative $100 \%$ modulus, different results are observed. After aging, the modulus of neat CR is increased due to the post curing effect whereas the modulus of neat NR is decreased due to the predominant chain scission induced by the thermal oxidative reaction. For rubber blends, the relative $100 \%$ modulus tends to decrease with increasing NR content due to the dilution effect. It could be observed that, at $75 / 25$ and $50 / 50 \mathrm{CR} / \mathrm{NR}$ ratios in which CR still remains the matrix, the effect of post curing in CR phase could override the effect of chain scission in NR phase giving rise to the increase in modulus after aging (the relative modulus is greater than 1). However, at 25/75 CR/NR ratio where NR becomes the matrix, the effect of chain scission is more pronounced than the post curing effect giving rise to the overall decrease in modulus after aging. Similar trend is also found for the relative hardness. The same explanation is applied.

The effect of blend ratio on oil resistance, represented in terms of the relative value, is depicted in Figure 7. Generally, CR is classified as a polar rub-

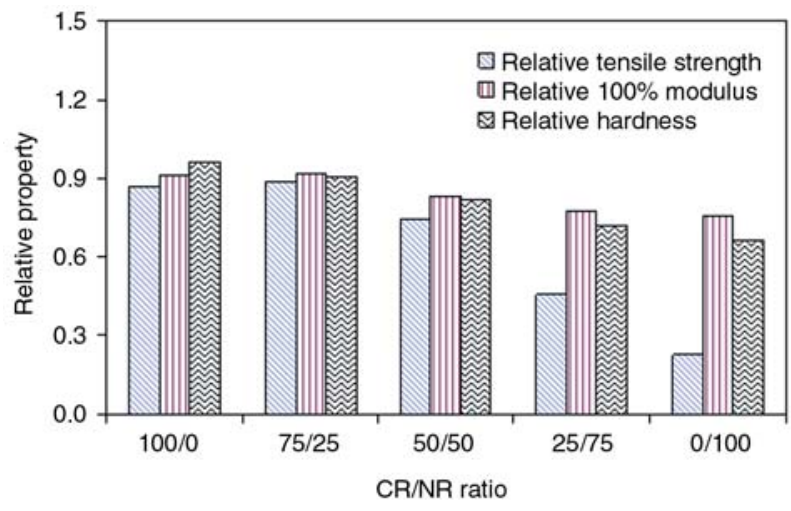

Figure 7. Effect of blend ratio on oil resistance (represented in terms of the relative properties) 


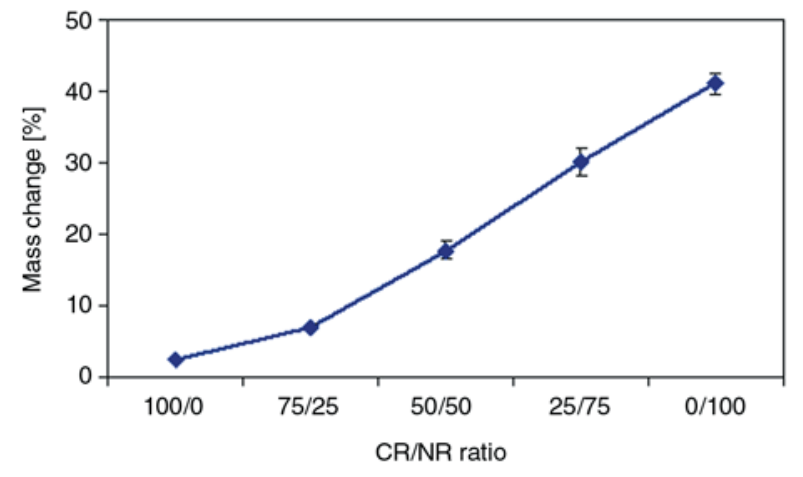

Figure 8. Dependence of oil resistance on blend ratio (represented in terms of the mass change)

ber due to the existence of chlorine $(\mathrm{Cl})$ atoms in its molecule. CR is therefore more resistant to oil compared to the non-polar NR as can be seen from the higher values of relative tensile strength, relative modulus as well as relative hardness. For rubber blends, good resistance to oil is achieved as long as CR still remains the matrix. This is found in $75 / 25$ and 50/50 CR/NR blends. For 25/75 CR/NR blend in which NR becomes the matrix, the oil resistance drops significantly. In addition to the relative properties, the oil resistance of the blends was also measured in terms of mass change after oil immersion and the results are given in Figure 8. As expected, the lowest mass change is found for neat $\mathrm{CR}$ and the highest mass change is found for neat NR. The mass change of the blends lies in between those of the individual blend partners. The higher the NR content in the blend, the greater the mass change or the poorer the oil resistance.

Ozone resistance of the rubber vulcanizates was also investigated and, after testing, the ozone cracks at the surface of the specimens were photographed as shown in Figure 9. Obviously, after exposing to $50 \mathrm{pphm}$ of ozone concentration for

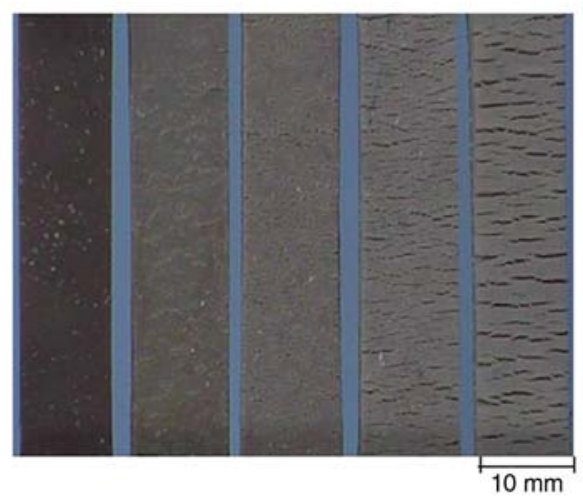

Figure 9. Influence of blend ratio on ozone resistance of CR/NR blends (from left to right: 100/0, 75/25, 50/50, 25/75 and 0/100)
70 hours, no visual crack is found on the specimen surface for neat $\mathrm{CR}$. The moderately high ozone resistance of CR arises from the lower reactivity of double bonds to ozone attack. However, for NR in which its double bonds are highly reactive to ozone attack, large and deep ozone cracks are found on the specimen surface. The severe ozone cracks are also found in 25/75 CR/NR blend in which NR is the matrix. Although the cracks are also observed in $75 / 25$ and $50 / 50 \mathrm{CR} / \mathrm{NR}$ blends, it could be observed that the cracks found in these blends are less severe, compared to neat NR. The higher the $\mathrm{CR}$ content in the blend, the greater the ozone resistance of the vulcanizate.

\section{Conclusions}

Taken as a whole, the results reveal that increasing NR content in the silica-filled CR/NR blend gives rise to the increases of Mooney viscosity and cure rate. However, the state of cure and, thus, modulus and hardness are found to reduce with increasing NR content. The degree of filler dispersion is also reduced with increasing NR content due to the poor interaction between non-polar NR and highly polar silica. The highest state of cure found in silicafilled CR is thought to arise from the additional crosslinks obtained from the chemical reaction between allylic $\mathrm{Cl}$ atoms of $\mathrm{CR}$ and the silanol groups on silica surface. Resistance to thermal aging, oil and ozone attack of the rubber blend is mainly governed by the blend morphology. It is found that, at 50/50 CR/NR ratio, the silica-filled $\mathrm{CR} / \mathrm{NR}$ blend possesses good mechanical properties in association with satisfactory aging and oil resistance because this blend still has CR as the matrix. At higher NR content, phase inversion takes place. Considerable reductions of both mechanical properties and resistance to degradation from thermal aging and oil are therefore observed. Although ozone cracks are found in all blends, great improvement in ozone resistance is observed when CR content is increased.

\section{References}

[1] Saad A. L. G., El-Sabbagh S.: Compatibility studies on some polymer blend systems by electrical and mechanical techniques. Journal of Applied Polymer Science, 79, 60-71 (2001).

[2] Helaly F. M., El-Sabbagh S. H.: Bone meal waste and $\mathrm{Ca}\left(\mathrm{HPO}_{4}\right)_{2}$ as reinforcing filler for $\mathrm{NR}$ and $\mathrm{CR}$ and 
their blends compared with conventional white filler. Journal of Elastomers and Plastics, 34, 335-348 (2002).

[3] Das A., Ghosh A. K., Basu D. K.: Evaluation of physical and electrical properties of chloroprene rubber and natural rubber blends. Kautschuk Gummi Kunststoffe, 58, 230-238 (2005).

[4] Ramesan M. T., Alex R., Khanh N. V.: Studies on the cure and mechanical properties of blends of natural rubber with dichlorocarbene modified styrene-butadiene rubber and chloroprene rubber. Reactive \& Functional Polymers, 62, 41-50 (2005).

[5] Hofmann W.: Rubber technology handbook. Hanser Publishers, Munich (1989).

[6] Tinker A. J., Jones K. P.: Blends of natural rubber: Novel techniques for blending with speciality polymers. Chapman \& Hall Ltd., London (1998).

[7] Choi S.: Improvement of properties of silica-filled natural rubber compounds using polychloroprene. Journal of Applied Polymer Science, 83, 2609-2616 (2002).

[8] Das A., Debnath S. C., De D., Basu D. K.: Evaluation of physical properties and curing characteristics of silica-filled ethylene-propylene-diene terpolymer in the presence of chloroprene rubber. Journal of Applied Polymer Science, 93, 196-200 (2004).
[9] Wang G., Li M., Chen X.: Effects of filler on mechanical properties of a water-swellable rubber. Journal of Applied Polymer Science, 72, 577-584 (1999).

[10] Sae-oui P., Sirisinha C., Thepsuwan U., Hatthapanit K.: Dependence of mechanical and aging properties of chloroprene rubber on silica and ethylene thiourea loadings, European Polymer Journal, 43, 185-193, 2007.

[11] Sae-oui P., Sirisinha C., Thepsuwan U., Hatthapanit K.: Role of silane coupling agents on properties of silica-filled polychloroprene. European Polymer Journal, 42, 479-486 (2006).

[12] Ismail H., Leong H. C.: Curing characteristics and mechanical properties of natural rubber/chloroprene rubber and epoxidized natural rubber/chloroprene rubber blends. Polymer Testing, 20, 509-516 (2001).

[13] Vanderbilt R. T.: The Vanderbilt rubber handbook (13 ${ }^{\text {th }}$ Edition). R. T. Vanderbilt Co. Ltd., Norwalk (1990).

[14] Byers J. T.: Silane coupling agents for enhanced silica performance. Rubber World, 218, 38-47 (1998).

[15] Sirisinha C., Sae-oui P., Guaysomboon J.: Mechanical properties, oil resistance and thermal aging properties in CPE/NR blends. Journal of Applied Polymer Science, 84, 22-28 (2002). 